EMANUEL FONSECA LIMA

O DIREITO DAS MUDANÇAS CLIMÁTICAS NA SOCIEDADE MUNDIAL

DISSERTAÇÃO DE MESTRADO

ORIENTADOR: PROFESSOR DOUTOR ORLANDO VILLAS

BÔAS FILHO

UNIVERSIDADE DE SÃO PAULO

FACULDADE DE DIREITO

São Paulo-SP

2017 



\title{
O DIREITO DAS MUDANÇAS CLIMÁTICAS NA SOCIEDADE MUNDIAL
}

Dissertação apresentada à Banca Examinadora do Programa de Pós-Graduação em Direito, da Faculdade de Direito da Universidade de São Paulo, como exigência parcial para obtenção do título de Mestre em Direito, na área de concentração Teoria Geral e Filosofia do Direito, sob a orientação do Prof. Dr. Orlando Villas Bôas Filho.

\section{UNIVERSIDADE DE SÃO PAULO}

\section{FACULDADE DE DIREITO}

\author{
São Paulo - SP
}


Catalogação da Publicação

Serviço de Biblioteca e Documentação

Faculdade de Direito da Universidade de São Paulo

Fonseca, Emanuel Lima

O direito das mudanças climáticas na sociedade mundial

/ Emanuel Fonseca Lima; orientador Orlando Villas Bôas

Filho -- São Paulo, 2017.

$115 \mathrm{f}$.

Dissertação (Mestrado - Programa de Pós-

Graduação em Teoria Geral e Filosofia do Direito) -

Faculdade de Direito, Universidade de São Paulo, 2017.

1. A sociedade mundial na teoria dos sistemas de Niklas Luhmann. 2. O Direito na teoria dos sistemas. 3. Mudanças climáticas e a teoria dos sistemas. 4. O transconstitucionalismo e o Direito das mudanças climáticas. I. Filho, Orlando Villas Bôas, orient. II. Título. 
Emanuel Lima Fonseca

O direito das mudanças climáticas na sociedade mundial

Aprovado em:<smiles>C[SiH2]</smiles>

BANCA EXAMINADORA:

Prof. Dr. Titular Orlando Villas Bôas Filho (Orientador)

Instituição: FD-USP

Assinatura:

Prof. Dr.:

Instituição:

Assinatura:

Prof. Dr.:

Instituição:

Assinatura: 
À minha amada Lívia, cujo amor, compreensão e incentivo têm sido minha fonte de constante inspiração. 


\section{AGRADECIMENTOS}

O mestrado na Faculdade de Direito do Largo São Francisco foi uma experiência extremamente gratificante e enriquecedora. Nessa empreitada, contei com colegas que, cada um à sua maneira, contribuíram para revelar perspectivas até então por mim desconhecidas.

Agradeço aos professores por terem compartilhado suas experiências e mostrado novas formas de pensar o Direito e aos colegas com quem foram divididos tantas dúvidas e pontos de vista.

Ao meu orientador, Professor Orlando Villas Bôas Filho, pelo voto de confiança e pelos valiosos conselhos que, desde a graduação, têm norteado minhas escolhas acadêmicas e aos colegas da Procuradoria Geral do Estado de São Paulo, cujo apoio e compreensão foram essenciais para a realização do curso.

Por fim, agradeço à minha família, meu pai, Tadeu, minha mãe, Auxilium, minha irmã, Lilian e minha noiva, Lívia, pelo carinho, paciência, apoio incondicional e por serem meu porto seguro nos momentos mais difíceis. 
"O progresso humano não é automático nem inevitável. Somos atualmente confrontados com o fato de o amanhã ser hoje, e colocados perante a urgência cruel do agora. Neste enigma da vida e da história é possível ser demasiado tarde.... Podemos gritar desesperadamente para que o tempo pare, mas o tempo ensurdece a cada súplica e continua a passar rapidamente. Sobre as ossadas descoradas e a mistura de restos de numerosas civilizações está escrita uma expressão patética: Demasiado tarde" - Martin Luther King Jr. 


\section{RESUMO}

LIMA, Emanuel Fonseca. O Direito das Mudanças Climáticas na Sociedade Mundial. 2017. 121 páginas. Mestrado - Faculdade de Direito, Universidade de São Paulo, São Paulo, 2017

O aquecimento global é o problema ecológico que, em razão da magnitude de suas consequências e do potencial de comprometer a qualidade e mesmo a existência de vida no planeta, tem recebido maior destaque nas agendas política, jurídica, científica e perante a opinião pública.

Ao analisar os desdobramentos éticos de tal questão, Stephen Gardiner se vale da metáfora de uma "tempestade perfeita", fruto da convergência de três grandes problemas que se reforçam mutuamente. Essa abordagem também pode ser aplicada ao Direito, o que permite identificar três grandes "tempestades jurídicas": a global, relacionada ao caráter transfronteiriço das mudanças climáticas; a temporal, que diz respeito à justiça intergeracional; e a teórica, decorrente da falta de teorias que possam fazer frente a esse desafio.

Se o Direito Ambiental já desenvolveu instrumentos que, a exemplo dos princípios da prevenção, precaução e solidariedade intergeracional, permitem lidar com relativo grau de sucesso com a tempestade global, o mesmo não pode ser dito em relação às outras duas.

Por essa razão, o presente trabalho busca analisar os caminhos existentes para que o Direito possa lidar com as tempestades global e teórica. Para tanto, adota como ponto de partida a Teoria dos Sistemas de Niklas Luhmann que, ao deixar de restringir o fenômeno jurídico à sua forma estatal de expressão, lança as bases para o desenvolvimento de teorias que permitam o tratamento de problemas jurídicos da sociedade mundial.

Com isso, torna-se possível o estudo das contribuições que o diálogo de ordens normativas proposto pelo Transconstitucionalismo de Marcelo Neves pode oferecer para o enfrentamento das mudanças climáticas e seus efeitos adversos.

Palavras-Chave: 1. Aquecimento Global. 2. Mudanças Climáticas. 3. Teoria dos Sistemas. 4. Transconstitucionalismo. 


\begin{abstract}
LIMA, Emanuel Fonseca. The Climate Change Law in the World Society. 2017. 121 páginas. Thesis (Master in Law) - Faculdade de Direito, Universidade de São Paulo, São Paulo, 2017
\end{abstract}

Because of the magnitude of its consequences and its potencial to undermine the quality or even the life itself in the Earth, global warming has been the most relevant ecological problem on the political, legal and scientific agenda and also to the public opinion.

When Stephen Gardiner analyses the ethics ramification of this such issue, he uses the "perfect storm" metaphor, resulting from the three big problems convergence that strengthen each other. This approach can be applied to the Law as well, which allows us to identifiy three big "legal storms": the global, related to the climate changes transboundary character; the temporal, due to the intergenerational justice; and the theorical, deriving from the theories lack that could face this such challenge.

If Environmental Law has already developed instruments that allow us to handle the global storm with a certain level of success, like the principles of prevention, precaution and solidarity intergenerational, we can not say the same about the other ones. That is the reason why the present paper aims to examine the ways in which the Law can deal with the global and theorical storms. To this end, it starts from the Niklas Luhmann's systems theory. Luhmann, after no longer restrict the legal phenomenon to the its state expression, lays down the theories basis to treat the world society legal problems.

Thereby, it is possible to study how the dialogue between the normatives orders proposed by Marcelo Neves in his Transconstitucionalism can contribute towards countering climate changes and its adverse effects.

Keywords: 1. Global warming; 2. Climate chances; 3 . Theory of systems; 4. Transconstitucionalism. 


\section{SUMÁRIO}

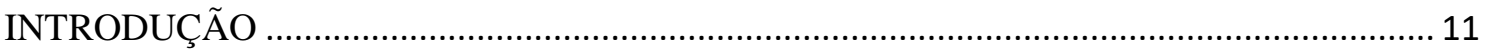

1 A SOCIEDADE MUNDIAL NA TEORIA DOS SISTEMAS DE NIKLAS LUHMANN..... 13

1.1 O Projeto de uma Teoria Para a Sociedade Moderna.......................................................... 13

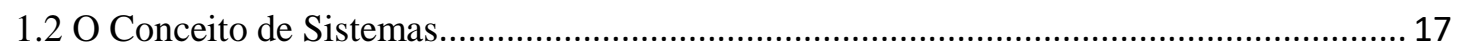

1.3 A Abertura Cognitiva e o Fechamento Operacional dos Sistemas..................................... 21

1.4 Tipos de Sistema: Vivo, Psíquico e Social.................................................................... 24

1.5 A Evolução do Sistema Social ..................................................................................... 26

1.5.1 Aspectos gerais da teoria da evolução....................................................................... 27

1.5.2 Evolução e diferenciação do sistema social .............................................................. 28

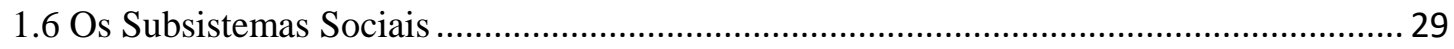

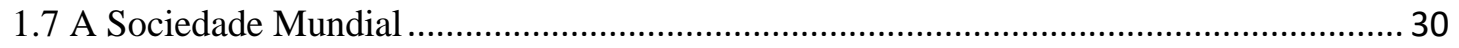

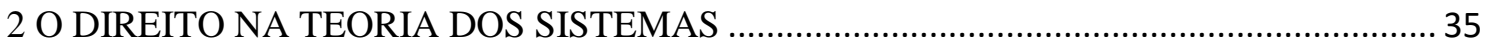

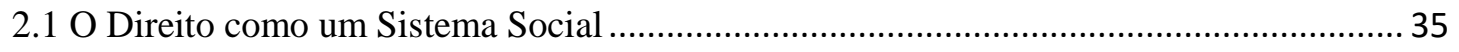

2.2 A Diferenciação e o Fechamento Operacional do Direito .................................................... 37

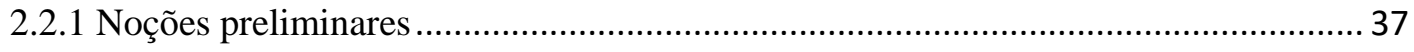

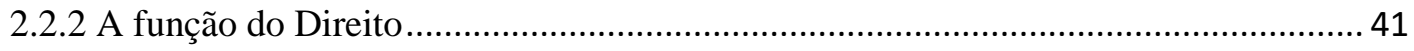

2.2.3 Codificação e programação do sistema jurídico........................................................ 44

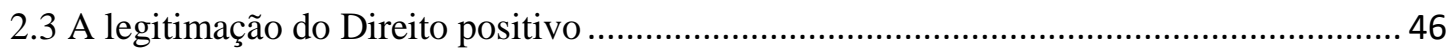

2.4 A Função de Regulação do Sistema Jurídico ................................................................. 48

2.5 Centro e Periferia do Sistema Jurídico ................................................................................ 49

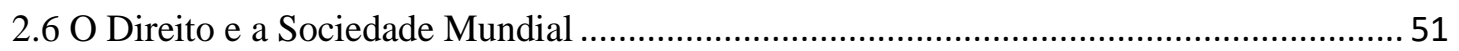

3.1 A Formação do Discurso sobre Questões Ecológicas ....................................................... 54

3.2 As Gerações de Problemas Ambientais....................................................................... 58

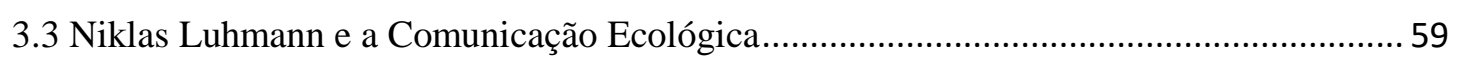

3.4 O Aquecimento Global à Luz da Teoria dos Sistemas................................................... 62

3.4.1 As mudanças climáticas e seus efeitos adversos ........................................................62 62

3.4.2 Eixos de enfrentamento do aquecimento global: mitigação e adaptação .................... 68

3.4.3 A evolução do tratamento do aquecimento global no Direito Internacional ............... 69

O período pós-Quioto é marcado por polêmicas e tentativas de elaboração de um acordo eficaz contra o aquecimento global e seus efeitos adversos................................................ 74

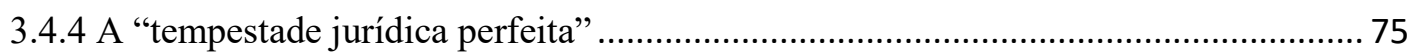

4 O TRANSCONSTITUCIONALISMO E O DIREITO DAS MUDANÇAS CLIMÁTICAS .. 85 


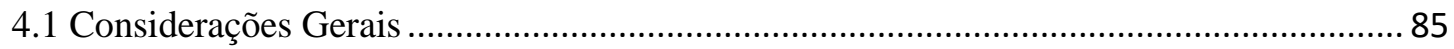

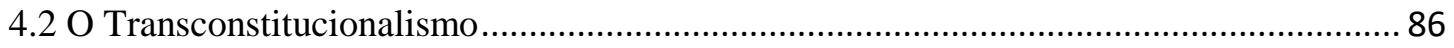

4.2.1 Acoplamento estrutural x racionalidade transversal................................................. 86

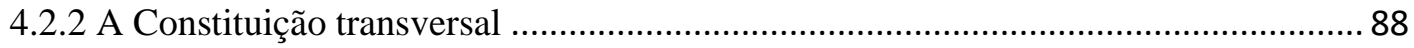

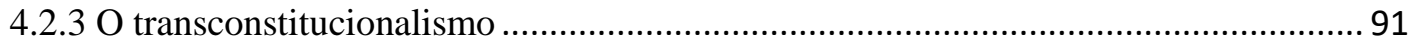

4.3 O Transconstitucionalismo e o Aquecimento Global........................................................... 95

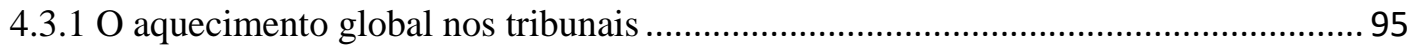

4.3.2 $\mathrm{O}$ transconstitucionalismo e o aquecimento global ................................................... 99

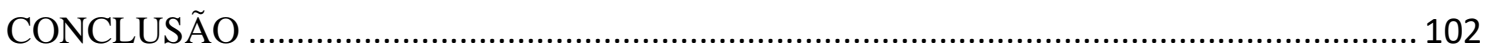

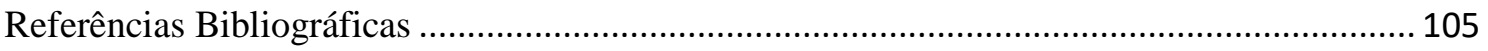




\section{INTRODUÇÃO}

Por séculos, a ideia de progresso foi associada a um modelo de crescimento econômico e desenvolvimento tecnológico pautado pela subjugação da natureza e exploração predatória dos recursos naturais, o que desencadeou não só problemas ecológicos como a poluição, mas também ameaças que são capazes de provocar impactos globais e ilimitados no tempo.

Entre elas, as mudanças climáticas, em razão da magnitude de suas consequências e do potencial de comprometer a qualidade e mesmo a existência de vida no planeta, são o problema ecológico que mais tem recebido destaque nas agendas política, jurídica e científica e perante a opinião pública.

Se por um lado alguns efeitos já têm sido notados, como a alteração do regime de chuvas e o aumento da frequência de fenômenos climáticos extremos; por outro lado, as previsões de cenários futuros são ainda mais desoladoras, apontando para, entre outras consequências, o desaparecimento de pequenos países insulares, alagamento de zonas costeiras e a intensificação de fluxos migratórios.

$\mathrm{O}$ aquecimento global tem representado um desafio extremamente tormentoso para o Direito. Como o ordenamento jurídico, segmentado primordialmente em Estados, pode fazer frente a um problema de caráter global, que extrapola seu âmbito de validade? De que forma os ordenamentos de países como Bangladesh ou Tuvalu, severamente afetados pelas consequências adversas do aquecimento global, podem lidar com um problema cujas principais causas não se encontram em seus territórios e jurisdições?

Melhor sorte não é reservada ao Direito Internacional que, apesar de oferecer importantes contribuições com a Convenção-Quadro das Nações Unidas sobre as Mudanças do Clima, ainda lida com sérias dificuldades de imposição e gritantes assimetrias de poder entre os Estados. As negociações para os acordos climáticos têm revelado profundos conflitos de interesses e concepções de países desenvolvidos, 
emergentes e pobres, o que dificulta a celebração de tratados com metas vinculantes, necessárias para fazer frente a tal desafio.

O presente trabalho tem como objetivo analisar aspectos jurídicos das mudanças do clima e as possibilidades oferecidas pelo transconstitucionalismo para lidar com as mudanças do clima.

A análise do aquecimento global não prescinde da adoção de um instrumental teórico arrojado, capaz de superar os obstáculos epistemológicos das teorias sociológicas clássicas e permitir a adequada compreensão da sociedade moderna. Esse referencial pode ser encontrado na teoria dos sistemas de Niklas Luhmann, razão pela qual sua concepção de sociedade e de direito será explicitada nos dois primeiros capítulos.

Em seguida, com o auxílio dessa teoria, passar-se-á ao estudo das mudanças climáticas, apontando seus principais impactos no entorno natural e a forma como as comunicações relativas a esse fenômeno são processadas no âmbito de sistemas sociais como o científico, o político, o econômico e o jurídico. Abordar-se-á, ainda, a insuficiência do Direito Estatal e Internacional para, isoladamente, superar os desafios decorrentes desse problema ecológico de segunda geração, típico da sociedade mundial.

Por fim, a pesquisa tratará dos limites e possibilidades do transconstitucionalismo proposto por Marcelo Neves para o enfrentamento do aquecimento global, analisando, para tanto, precedentes judiciais de cortes estatais e internacionais. 


\section{CONCLUSÃO}

Nas últimas décadas do século $\mathrm{XX}$, as consequências de uma crise ecológica, fruto da exploração predatória dos recursos naturais, passaram a ser percebidas e amplamente processadas no âmbito de sistemas sociais como a Ciência, Política, Economia e o Direito. Entre esses problemas, as mudanças do clima se mostram o de maior gravidade, em razão de seu caráter transfronteiriço, da magnitude de seus impactos e da dissociação do local de produção das causas e a ocorrência de seus efeitos.

Stephen Gardiner, ao tratar dos desdobramentos éticos do aquecimento global, se vale da metáfora de uma "tempestade moral perfeita", fruto da convergência de três problemas morais distintos (representados por "tempestades"), que, por se reforçarem mutuamente, criam desafios sem precedentes.

Essa abordagem também pode ser utilizada no âmbito do Direito, permitindo a identificação de três "tempestades jurídicas". A primeira delas, a global é relacionada ao aspecto espacial transfronteiriço e ao quadro de injustiça climática desse fenômeno, na medida em que aqueles que menos contribuíram para sua ocorrência e com menor capacidade de adaptação são os que sofrerão de forma mais drástica as suas consequências.

Além disso, o aquecimento global é um problema ecológico cujos efeitos se perpetuam no tempo, afetando não só a atual, mas também, e talvez de forma ainda mais drástica, as futuras gerações. É nesse aspecto temporal que reside a segunda das “tempestades jurídicas". Ela também se relaciona aos princípios da prevenção e da precaução, que demandam atitudes para evitar um dano futuro.

Por fim, a última tempestade, a teórica, diz respeito à ausência de instrumentos teóricos adequados para fazer frente aos desafios impostos pelo aquecimento global.

O Direito Ambiental desenvolveu mecanismos que, a exemplo dos princípios da prevenção, precaução e solidariedade intergeracional, já consagrado nos ordenamentos estatais e em tratados internacionais, permitem o enfrentamento da tempestade temporal. 
A questão, entretanto, se torna mais espinhosa quando as atenções se voltam para as tempestades teórica e global. Para enfrentá-las, é imprescindível um instrumental teórico arrojado, capaz de lidar com a complexidade das questões atinentes à sociedade moderna. Essa tarefa é bem desempenhada pela Teoria dos Sistemas de Niklas Luhmann que, ao buscar a superação dos obstáculos epistemológicos das teorias sociológicas clássicas, em especial, o preconceito territorial, possibilita a análise de um problema que transcende as fronteiras dos Estados.

Além disso, ao conceber o Direito como um sistema autopoiético, guiado pelo código lícito/ilícito e encarregado com exclusividade da estabilização de expectativas normativas nas dimensões temporal, objetiva e social de sentido, Luhmann rompe com as abordagens tradicionais, deixando de restringir o fenômeno jurídico à sua forma estatal de expressão e lançando as bases para o desenvolvimento de teorias para o tratamento de problemas jurídicos da sociedade mundial.

Entre essas teorias, destaca-se a do transconstitucionalismo, desenvolvida por Marcelo Neves. De acordo com ela, as várias ordens que compõem o sistema jurídico (estatal, internacional, supranacional e extraestatal) mostram-se incapazes de, isoladamente, oferecer respostas complexamente adequadas para os problemas normativos da sociedade mundial.

Em razão disso, o autor se vale da ideia de racionalidade transversal para lançar um novo olhar sobre a noção de Constituição, passando a concebê-la não mais como um simples acoplamento estrutural entre os sistemas jurídicos e políticos, mas como um mecanismo que viabiliza pontes entre esses dois sistemas, possibilitando o aprendizado recíproco e o intercâmbio entre as racionalidades já processadas em cada um deles.

A partir desses pressupostos, desenvolve a noção de transconstitucionalismo, modelo que permite a "conversação" entre diferentes ordens jurídicas a fim de que problemas constitucionais comuns a elas possam ser enfrentados sem a imposição de uma sobre as demais. Uma de suas principais formas de expressão é a invocação de precedentes de uma corte constitucional perante outras, não enquanto decisões de caráter vinculante, mas como elementos de persuasão.

Essa abordagem ganha relevância se considerado que, na sociedade mundial, uma mesma controvérsia de direitos fundamentais pode se apresentar perante ordens 
jurídicas diferentes e se inserir no âmbito de competência de seus tribunais, o que torna inadequada uma postura provincialista por parte de qualquer uma delas.

No caso específico do aquecimento global, isso é evidenciado pela impossibilidade de as ordens jurídicas estatais lidarem com problemas que extrapolam seu âmbito de validade e pela notória dificuldade de imposição do Direito Internacional, especialmente quando conflitante com os interesses de potências como os Estados Unidos, China e Rússia.

Além disso, as mudanças do clima afetam direitos fundamentais como a vida, a saúde e um meio ambiente ecologicamente equilibrado e as discussões a respeito das medidas de mitigação e adaptação a tal fenômeno guardam estreita relação com as questões de limitação e organização do poder, o que torna inquestionável seu caráter constitucional.

Também é verdade que os litígios que direta ou indiretamente versam sobre o aquecimento global ainda são escassos e recentes, sendo um tanto quanto prematura a identificação neles de ocorrência efetiva do transconstitucionalismo. No entanto, isso não significa que essa teoria não possa fornecer aportes interessantes para a solução de tais controvérsias, na medida em que as decisões de um tribunal podem oferecer elementos valiosos para a apreciação de casos similares por outra corte.

Pode-se mencionar, como exemplo, a consideração do aquecimento global para interpretação e aplicação de normas ambientais, tal como ocorrido em decisões do Superior Tribunal de Justiça Brasileiro e da Alta Corte Federal da Nigéria; a consagração, em decisão proferida pela Corte Constitucional da Colômbia, do dever estatal de proteção de ambientes estratégicos para desaceleração das mudanças do clima; a determinação feita pela Suprema Corte dos Estados Unidos e pela Corte Superior de King County para que agências governamentais adotem medidas de monitoramento de gases de efeito estufa ou a decisão da Corte Distrital de Haia que consignou que a baixa contribuição de um país para as mudanças climáticas não afeta seu dever de adotar as medidas necessárias para mitigar esse fenômeno.

Assim, o transconstitucionalismo se mostra a alternativa mais viável para que as diferentes ordens jurídicas possam fazer frente a um problema que, a exemplo do aquecimento global, transcende as fronteiras dos Estados. 


\section{Referências Bibliográficas}

ACSELRAD, Henri. Justiça Ambiental - novas articulações entre meio ambiente e democracia. Rio de Janeiro: Ibase, 2000. Disponível em: $<$ http://www.justicaambiental.org.br/_justicaambiental/pagina.php?id=497>. Acesso em: 24 mar. 2011.

. Ambientalização das lutas sociais - o caso do movimento por justiça ambiental.

São Paulo, 2010a. Disponível em:

<http://www.justicaambiental.org.br/_justicaambiental/pagina.php?id=497>. Acesso em: 24 mar. 2011.

. Vulnerabilidade ambiental, processos e relações. In: FERREIRA, Heline Sivini; LEITE, José Rubens Morato; BORATTI, Larissa Verri. Estado de Direito Ambiental: Tendências. 2. ed. Rio de Janeiro: Forense, 2010b.

ACSELRAD, Henri; MELLO, Cecília Campello do A; BEZERRA, Gustavo das Neves. O que é justiça ambiental?. Rio de Janeiro: Garamond, 2009.

ALCOVER, Pilar Gimenez. El derecho em la teoria de la sociedad de Niklas Luhmann. Barcelona: Bosch, 1993.

ALIER, Joan Martínez. O ecologismo dos pobres: conflitos ambientais e linguagens de valoração. Tradução de Maurício Waldman. São Paulo: Contexto, 2007.

ALVARENGA, Luciano José. Vivenciar as paisagens, fruir os lugares: a dimensão ecológico-paisagística da dignidade humana e a justiça socioambientel. In: SAAVEDRA, Pedro Curvello; AVZARADEL, Giulia Parola; VAL, Eduardo Manuel (org). Democracia ambiental na América Latina: uma abordagem comparada. Rio de Janeiro: Multifoco, 2016.

ARNAUD, André-Jean. O direito entre modernidade e globalização: lições de filosofia do Direito e do Estado. Tradução de Patrice Charles Wuillaume. Rio de Janeiro: Renovar, 1999. 
ARAGÃO, Alexandra. Direito constitucional do ambiente da União Europeia. In: LEITE, José Rubens Morato; CANOTILHO, José Joaquim Gomes (org.). Direito Constitucional Ambiental Brasileiro. São Paulo: Saraiva, 2010.

Ultrapassar o défice ecológico em tempo de crise (económica): breves reflexões o dever de restauração de habitats. In: MONTERO, Carlos Eduardo Peralta; ALVARENGA, Luciano José; AUGUSTIN, Sérgio. Direito e justiça ambiental: diálogos interdisciplinares sobre a crise ecológica. Caxias do Sul: Educs, 2014.

BATES, Bryson Craig; KUNZEWICZ, Zbigniew W.; WU, Shaohong; PALUTIKOF, Jean. El cambio climático y el agua. Documento técnico del Grupo Intergubernamental de Expertos sobre el Cambio Climático, Secretaría del IPCC. Ginebra, 2008.

BECK, Ulrich. Sociedade de risco: rumo a uma outra modernidade. São Paulo: Editora $34,2010$.

BECKERMAN, Wilfred; PASEK, Joanna. Justice, posterity and the environment. Oxford: Oxford University Press, 2001.

BERGÉ, Pierre; POMEAU, Yves; DUBOIS-GANCE, Monique. Dos ritmos ao caos. São Paulo, UNESP, 1996.

BIRNIE, Patricia; BOYLE, Alan; REDGWELL, Catherine. International Law and the environment. Oxford: Oxford University Press, 2009.

BOBBIO, Norberto. El tercero ausente. Madrid: Catedra Teorema, 1997.

. Direita e esquerda. 2. ed. São Paulo: UNESP, 2001.

BORRAS PENTINAT, Susana. La justicia climática: entre la tutela y la fiscalización de las responsabilidades. Anu. Mex. Der. Inter. México, v. 13, p. 03-49, dic. $2013 . \quad$ Disponível em: <http://www.scielo.org.mx/scielo.php?script=sci_arttext\&pid=S1870$46542013000100001 \& \operatorname{lng}=e s \& n r m=i s o>$. Acesso em: 04 jan. 2017.

BROCK, Lothar. World society from the bottom up. In: ALBERT, Mathias; HILKERMEIRE, Lena. Observing international relations: Niklas Luhmann and World Politics. London: Routledge, 2004. 
CAMPILONGO, Celso Fernandes. Política, sistema jurídico e decisão judicial. São Paulo: Max Limonad, 2002.

. Direito e diferenciação social. São Paulo: Saraiva, 2011.

Interpretação do Direito e movimentos sociais. Rio de Janeiro: Elsevier, 2012.

CANOTILHO, José Joaquim Gomes. Direito Constitucional Ambiental Português: tentativa de compreensão de 30 anos das gerações ambientais no Direito Constitucional Português: In:7 LEITE, José Rubens Morato; CANOTILHO, José Joaquim Gomes (org.). Direito Constitucional Ambiental Brasileiro. São Paulo: Saraiva, 2010 .

. Estado constitucional ecológico e democracia sustentada. In: FERREIRA, Heline Sivini; LEITE, José Rubens Morato; BORATTI, Larissa Verri. Estado de direito ambiental: tendências. 2. ed. Rio de Janeiro: Forense, 2010b.

CARSON, Rachel. Primavera silenciosa. São Paulo: Melhoramentos, 1962.

CARVALHO, Delton Winter de. Mudanças Climáticas e as implicações jurídicoprincipiológicas para a gestão dos danos ambientais futuros numa sociedade de risco global. In: LAVRATTI, Paula; PRESTES, Vanêsca Buzelato (org.). Direito e mudanças climáticas: responsabilidade civil e mudanças climáticas. São Paulo: Instituto O Direito por um Planeta Verde, 2010.

A formação sistêmica do sentido jurídico do meio ambiente. In: SCHWARTZ, Germano (org). Juridicização das esferas sociais e fragmentação do Direito na sociedade contemporânea. Porto Alegre: Livraria do Advogado Editora, 2012.

CLARO, Carolina de Abreu Batista. O aporte jurídico do direito dos refugiados e a proteção internacional dos "refugiados ambientais". Cosmopolitan Law Journal / Revista de Direito Cosmopolita, 1 dez. 2013. Disponível em: <http://www.epublicacoes.uerj.br/index.php/rdcuerj/article/view/5760/6413>. Acesso em: 12 nov. 2015 .

CORSI, Giancarlo; ESPOSITO, Elena; BARALDI, Claudio. Glosario sobre la teoria Social de Niklas Luhmann. Tradução de Miguel Romero Pérez e Carlos Villalobos. México: Universidade Iberoamericana, 1996. 
DE GIORGI, Raffaele. Direito, democracia e risco: vínculos com o futuro. Porto Alegre: Sergio Antonio Fabris Editor, 1998.

Direito, tempo e memória. São Paulo: Quartier Latin, 2006.

DELMAS-MARTY, Mireille. Por um Direito comum. São Paulo: Martins Fontes, 2004. Ordering Pluralism: a conceptual framework for understanding the transnational legal world. Portland: Hart Publishing, 2009.

EHRLICH, Eugen. Fundamentos da sociologia do Direito. Brasília: UnB, 1986.

FARENA, Maritza N. Ferretti C. Algumas notas sobre direitos humanos e migrantes. In: ROCHA, João Carlos de Carvalho; HENRIQUES FILHO, Tarcísio Humberto Parreira; CAZETTA, Ubiratan. Direitos humanos: desafios humanitários contemporâneos. Belo Horizonte: Del Rey, 2008.

FENSTERSEIFER, Tiago. Direitos fundamentais e proteção do meio ambiente: a dimensão ecológica da dignidade humana no marco jurídico-constitucional do Estado Socioambiental de Direito. Porto Alegre: Livraria do Advogado, 2008.

A responsabilidade do Estado pelos danos causados às pessoas atingidas pelos desastres ambientais ocasionados pelas mudanças climáticas: uma análise à luz dos deveres de proteção ambiental do Estado e da correspondente proibição de insuficiência na tutela do direito fundamental ao ambiente. In: LAVRATTI, Paula; PRESTES, Vanêsca Buzelato (org.). Direito e mudanças climáticas: responsabilidade civil e mudanças climáticas. São Paulo: Instituto O Direito por um Planeta Verde, 2010.

FIGUEIREDO, Guilherme José Purvin de. A propriedade no Direito Ambiental. 4. ed. rev. atual e amp. São Paulo: Editora Revista dos Tribunais, 2010.

FITZMAURICE, Malgosia. Contemporary issues in internation nvironmental Law. Cheltenham: Edward Elgar, 2009.

FLORES, Maria del Luján. La obligación del Estado de reparar los daños transfronterizos. Montevidéu: Carlos Alvarez Editor, 2005. 
FREITAS, Vladimir Passos de; FREITAS, Gilberto Passos de. Crimes contra a natureza. 9. ed. São Paulo: Editora Revista dos Tribunais, 2012.

FULLER, Lon Luvois, The Morality of Law. Revised Edition, New Haven, USA: Yale University Press, 1964.

GARDINER, Stephen M. The perfect moral storm: the ethical tragedy of climate change. Oxford: Oxford University Press, 2011.

GONÇALVES, Guilherme Leite. Direito entre certeza e incerteza: horizontes críticos para a teoria dos sistemas. São Paulo: Saraiva, 2013.

HART, Herbert Lionel Adolphus. O conceito de direito. São Paulo: Martins Fontes, 2009.

INTERGOVERNMENTAL PANEL ON CLIMATE CHANGE. Climate Change 2007: Synthese Report. Valencia, 2007.

Climate Change 2014: Synthese Report. Genebra, 2015.

IZUZQUIZA, Ignácio. Introducción: La urgencia de una nueva lógica. In: LUHMANN, Niklas. Sociedad y sistema: la ambición de la teoria. Barcelona: Ediciones Paidós Ibérica S.A, 1990.

La sociedad sin hombres: Niklas Luhmann o la teoría como escándalo. Barcelona: Anthropos Editorial, 2008.

KELSEN, Hans. Teoria geral do Direito e do Estado. 4. ed. São Paulo: Martins Fontes, 2005.

. Teoria pura do Direito. São Paulo: Martins Fontes, 2009.

KELSEN, Hans; CAMPAGNOLO; Umberto. Direito Internacional e Estado soberano. São Paulo: Martins Fontes, 2002.

KOLBERT, Elizabeth. Field notes from a catastrophe: climate change - is time running out? London: Bloomsbury Paperback, 2006. 
LEITE, José Rubens Morato; AYALA, Patrick de Araújo. Dano ambiental. Do individual ao coletivo extrapatrimonial. Teoria e prática. 3. ed. rev., atual. e amp. São Paulo: Editora Revista dos Tribunais, 2010.

LEITE, José Rubens Morato; FERREIRA, Heline Sivini. Tendências e perspectivas do Estado de Direito Ambiental no Brasil. In: FERREIRA, Heline Sivini; LEITE, José Rubens Morato; BORATTI, Larissa Verri. Estado de Direito Ambiental: tendências. 2. ed. Rio de Janeiro: Forense, 2010a.

Sociedade de risco e Estado. In: LEITE, José Rubens Morato; CANOTILHO, José Joaquim Gomes (org.). Direito Constitucional Ambiental Brasileiro. São Paulo, Saraiva, 2010b.

LEMOS, Patrícia Faga Iglecias. Mudanças climáticas e responsabilidade civil por dano ao meio ambiente. In: LAVRATTI, Paula; PRESTES, Vanêsca Buzelato (org.). Direito e mudanças climáticas: responsabilidade civil e mudanças climáticas. São Paulo: Instituto O Direito por um Planeta Verde, 2010.

Meio ambiente e responsabilidade civil do proprietário: análise do nexo causal. 2. ed. São Paulo: Editora Revista dos Tribunais, 2012.

LORENZETTI, Ricardo Luis. Teoría del derecho ambiental. Bogotá: Temis, 2011.

LOVELOCK, James. The state of the Earth: the revenge of Gaia. New York: Basic, 2006. LUHMANN, Niklas. Sociologia do Direito I. Rio de Janeiro: Edições Tempo Brasileiro, 1983a.

. Sociologia do Direito II. Rio de Janeiro: Edições Tempo Brasileiro, 1983 b.

The autopoiesis of social systems. In. LUHMANN, Niklas. Essays on selfreference. New York: Columbia University Press, 1990a.

. The "state" of political system. In. LUHMANN, Niklas. Essays on selfreference. New York: Columbia University Press, 1990b.

The world society as a social system. In. LUHMANN, Niklas. Essays on selfreference. New York: Columbia University Press, 1990c. 
Meaning as a sociology's basic concept. In. LUHMANN, Niklas. Essays on selfreference. New York: Columbia University Press, 1990d.

Sociología del riesgo. Guadalajara: Univ.de Guadalajara, 1992.

Novos desenvolvimentos na teoria dos sistemas. In: NEVES, Clarissa Eckert Baeta; SAMIOS, Eva Machado Barbosa (org.). Niklas Luhmann: a nova teoria dos sistemas. Porto Alegre: Editora da UFRGS; |Instituto Goethe, 1997a.

O conceito de sociedade. In: NEVES, Clarissa Eckert Baeta; SAMIOS, Eva Machado Barbosa (org.). Niklas Luhmann: a nova teoria dos sistemas. Porto Alegre: Editora da UFRGS; Instituto Goethe, 1997b.

. Por que uma 'teoria dos sistemas'?. In: NEVES, Clarissa Eckert Baeta; SAMIOS, Eva Machado Barbosa (org.). Niklas Luhmann: a nova teoria dos sistemas. Porto Alegre: Editora da UFRGS; Instituto Goethe, 1997c.

Sobre os fundamentos teóricos-sistêmicos da teoria da sociedade. In: NEVES, Clarissa Eckert Baeta; SAMIOS, Eva Machado Barbosa (org.). Niklas Luhmann: a nova teoria dos sistemas. Porto Alegre: Editora da UFRGS; Instituto Goethe, 1997d.

A sociedade mundial como sistema social. In: Lua Nova. 1999, nº 47, p. 179200.

El derecho de la sociedad. México: Universidad Iberoamericana, 2002

A restituição do décimo segundo camelo: do sentido de uma análise sociológica do direito. In: ARNAUD, André-Jean: LOPES Jr., Dalmir. Niklas Luhmann: do sistema social à sociologia jurídica. Rio de Janeiro: Lumen Juris, 2004.

La sociedad de la sociedad. Cidade do México: Herder, 2006

Introdução à teoria dos sistemas. Petrópolis: Vozes, 2009

MACCHI, Mirjan. Indigenous and traditional peoples and climate change. IUCN, 2008.

Disponível em: $<$ http://cmsdata.iucn.org/downloads/indigenous_peoples_climate_change.pdf>. Acesso em: 10 mar. 2012. 
MACÍAS, Luis Fernando. El derecho del cambio climático: un nuevo paradigma del derecho?. In: PACHÓN, María del Pilar García; NAVAS, Oscar Dario Amaya. Derecho y Cambio Climático. Bogotá: Universidad Externado de Colombia, 2010.

MARTUCCELLI, Danilo. Sociologías de la modernidad. Santiago: Lom Ediciones, 2013.

MEADOWS, Donella H; MEADOWS, Dennis L; RANDERS, Jorgen; BEHRENS III, William W. The limits of growth: a report for The Club of Rome's Project on the predicament of mankind. New York, Universe Books, 1972.

MCCORMICK, J. Rumo ao paraíso - a história do movimento ambientalista. Rio de Janeiro: Relume-Dumará, 1992.

NAFARRATE, Javier Torres. La sociología del derecho de Niklas Luhmann. In: KROTZ, Estabam (org.). Antropología jurídica: perspectivas socioculturales en el estudio del Derecho. México: Universidad Autónoma Metropolitana - Iztapalapa, 2002.

NAVAS, Oscar Darío Amaya. Hacia uma lectura jurídica del cambio climático. In: PACHÓN, María del Pilar García; NAVAS, Oscar Dario Amaya. Derecho y Cambio Climático. Bogotá: Universidad Externado de Colombia, 2010.

NEVES, Marcelo. Entre Têmis e Leviatã: uma relação difícil. São Paulo: Martins Fontes, 2006.

A constitucionalização simbólica. São Paulo: Martins Fontes, 2007.

Transconstitucionalismo. São Paulo: Martins Fontes, 2009.

NETHERLANDS. THE HAGUE DISTRICT COURT. C/09/456689. 24 jun. 2015. Urgenda Foundation v. Kingdom of the Netherlands. Disponível em: <http://wordpress2.ei.columbia.edu/climate-change-litigation/non-us-case/urgendafoundation-v-kingdom-of-the-netherlands/>. Acesso em: 4 jan. 2017.

NIGERIA. Federal Hight Court of Nigeria in The Benin Judicial Division. Suit $\mathrm{n}^{\mathrm{o}}$ : FHC/B/CS/53/05. Gbemre v. Shell Petroleum Development Company of Nigeria Ltd, et 
al. 14 nov. 2005. Disponível em: <http://wordpress2.ei.columbia.edu/climate-changelitigation/non-us-case/gbemre-v-shell-petroleum-development-company-of-nigeria-ltdet-al/>. Acesso em: 4 jan. 2017.

NORGAARD, Richard B; SRINIVASAN, U. Thara; CAREY, Susan P; HALLSTEIN, Eric; HIGGINS, Paul A.T.; KERR, Amber C; KOTEEN, Laura E; SMITH, Adam B; WATSON, Reg; HARTE, John. The debt of nations and the distribution of ecological impacts from human activities. Proceedings of the National Academy of Sciences. Palo Alto: Stanford University Highwire Press, 2008. Disponível em: <http://www.pnas.org/content/105/5/1768>. Acesso em: 08 jan.2017.

PNUD. Relatório de desenvolvimento humano 2007: combater as alterações climáticas: solidariedade humana em um mundo dividido. Lisboa: IPAD, 2007.

ROCHOLL, Martin. From Environmental Space to Ecological Debt - an European Perspective. Conference 'Globalisation, Ecological Debt, Climate Change and Sustainability'. Benin, 2001. Disponível em: <www.worldsummit2002.org/texts/EnvSpaceToEcoDebt.pdf>. Acesso em: Acesso em: 24 mar. 2011.

RODRIGUES, Leo Peixoto; NEVES, Fabrício Monteiro. Niklas Luhmann: a sociedade como sistema. Porto Alegre: EDIPUCRS, 2012.

ROMESÍN, Humberto Maturana; GARCÍA, Francisco J. Varela. De máquinas y seres vivos - autopoiesis: la organización de lo vivo. 5. ed. Santiago: Editora Universitária, 1998.

RUETER, Gero. Peruvian farmer sues German energy firm RWE. Deutsche Welle. 24 nov. 2016. Disponível em: <http://www.dw.com/en/peruvian-farmer-sues-germanenergy-firm-rwe/a-36506880>. Acesso em: 1 jan. 2017.

SABBAG, Bruno Kerlakian. O Protocolo de Quioto e seus créditos de carbono: manual jurídico brasileiro de mecanismo de desenvolvimento limpo. 2. ed. São Paulo: Ltr, 2009.

SARLET, Ingo Wolfgang; FENSTERSEIFER, Tiago. Direito Constitucional Ambiental: estudos sobre a Constituição, os direitos fundamentais e a proteção do meio ambiente. São Paulo: Ed. Revista dos Tribunais, 2011. 


\section{SECRETARIA DE ASSUNTOS ESTRATÉGICOS DA PRESIDÊNCIA DA} REPÚBLICA. Adaptação à mudança do clima: o quadro das negociações climáticas. n. 1. Brasília: Secretaria de Assuntos Estratégicos da Presidência da República, 2014.

SINGER, Peter. Libertação Animal. São Paulo: WMF Martins Fontes, 2010.

SLAUGHTER, Anne-Marie. Judicial globalization. Virginia Journal of International Law. Charlottesville, v. 40, p. 1.103-1124, 2000. Disponível em: <http://www.princeton. edu/ slaughtr/Articles/VJIL.pdf>. Acesso em: 20 jun. 2015.

SOARES, Guido Fernando Silva. Curso de Direito Internacional Público. v.1. São Paulo: Atlas, 2002.

A proteção internacional do meio ambiente. Barueri: Manole, 2003.

SPENCER-BROWN, Geroge. The laws of form. New York: The Julian Press, 1972.

STEIGLEDER, Annelise Monteiro. A imputação de responsabilidade civil por danos ambientais associados às mudanças climáticas. In: Direito e mudanças climáticas: responsabilidade civil e mudanças climáticas. LAVRATTI, Paula; PRESTES, Vanêsca Buzelato (org.). São Paulo: Instituto O Direito por um Planeta Verde, 2010. Disponível em:

$<\mathrm{http}: / / \mathrm{www}$.planetaverde.org/mudancasclimaticas/index.php?ling=por\&cont=publicac oes>. Acesso em: 20 ago. 2015.

STRENGERS, Isabelle. No tempo das catástrofes. Tradução de Eloisa Araújo Ribeiro. São Paulo: Cosac Naify, 2015.

TEUBNER, Gunther. Global Bukowina: Legal pluralism in the world society. In: TEUBNER, Gunther. Global Law without a state. Aldershot: Dartmouth Publishing Company, 1997.

El Derecho como sistema autopoietico de la sociedad global. Bogotá: Universidad Externado de Colombia, 2005.

USA. Supreme Court of the United States. Certiorari to the United States Court of Appeals for the District of Columbia Circuit. n. 05-1120. Massachusetts, et al. v 
Environmental Protection Agency, et al. 2 abr. 2007. Disponível em: <https://www.law.cornell.edu/supct/html/05-1120.ZS.html>. Acesso em: 4 jan. 2017.

. United States Court of Appeals for the ninth Circuit. Appeal from the United States District Court for the Northern District of California. No No. 09-17490. Native Village of Kivalina v. ExxonMobil Corp. 21 set. 2012. Disponível em: $<$ http://wordpress2.ei.columbia.edu/climate-change-litigation/case/native-village-ofkivalina-v-exxonmobil-corp/>. Acesso em: 4 jan. 2017.

State of Washington - King County Superior Court. n. 14.02.25295-1. 16 mai. 2016. Foster v. Washington Department of Ecology. Disponível em: $<$ http://wordpress2.ei.columbia.edu/climate-change-litigation/case/foster-v-washingtondepartment-of-ecology/>. Acesso em: 4 jan. 2016.

VEIGA, José Ely da. A desgovernança mundial da sustentabilidade. São Paulo: Editora 34, 2013.

VILLAS BÔAS FILHO, Orlando. O Direito na Teoria dos Sistemas de Niklas Luhmann. São Paulo: Max Limonad, 2006.

. Teoria dos sistemas e o Direito brasileiro. São Paulo: Saraiva, 2009.

. Uma teoria sociológica da justiça: Niklas Luhmann e a justiça como fórmula de contingência. Revista da Escola Superior da Procuradoria Geral do Estado. v. 4. n. 1. 2013

VILLAS BÔAS FILHO, Orlando; GONÇALVES, Guilherme Leite. Teoria dos sistemas sociais: Direito e sociedade na obra de Niklas Luhmann. São Paulo: Saraiva, 2013.

VIOLA, Eduardo José. Evolução da mudança climática na agenda internacional e transição para uma economia de baixo carbono, 2990-2009. In: FERREIRA, Heline Sivini; LEITE, José Rubens Morato; BORATTI, Larissa Verri. Estado de Direito Ambiental: tendências. 2. ed. Rio de Janeiro: Forense, 2010.

WILENSKY, Meredith. Climate change in the courts: an assesment of non-U.S. Climate litigation. New York: Sabin Center for Climate Change Law, 2015. 